\title{
The Risk of Parkinson Disease Associated with Urate in a Community-Based Cohort of Older Adults
}

\author{
S. Jain ${ }^{a, c}$ T.G. Ton ${ }^{\text {e }}$ R.M. Boudreau ${ }^{b} \quad$ M. Yang ${ }^{b}$ E.L. Thacker ${ }^{f} \quad$ S. Studenski $^{d}$ \\ W.T. Longstreth, Jr. ${ }^{\text {e }}$ E.S. Strotmeyer ${ }^{b}$ A.B. Newman ${ }^{b, d}$ \\ a Pittsburgh Institute for Neurodegenerative Diseases, ${ }^{b}$ Department of Epidemiology, University of Pittsburgh \\ Graduate School of Public Health, and 'Department of Neurology, d University of Pittsburgh School of Medicine, \\ Pittsburgh, Pa., and Departments of ${ }^{\mathrm{e}}$ Neurology and ${ }^{\mathrm{f}}$ Epidemiology, University of Washington, Seattle, Wash., USA
}

\section{Key Words}

Parkinson disease $\cdot$ Risk factors $\cdot$ Oxidative stress $\cdot$

Epidemiology $\cdot$ Uric acid

\begin{abstract}
Background/Aims: Studies suggest an inverse association between urate concentration and the risk of Parkinson disease (PD). We investigated this in the Cardiovascular Health Study in an elderly community-based cohort of adults. Methods: The association of baseline urate ( $\mu \mathrm{mol} / \mathrm{l})$ and incident PD over 14 years was assessed with locally weighted scatterplot smoothing (LOESS) regression from which categories of low $(<300 \mu \mathrm{mol} / \mathrm{l})$, middle (300-500 $\mu \mathrm{mol} / \mathrm{l})$, and high $(>500 \mu \mathrm{mol} / \mathrm{l})$ urate ranges were derived. Multivariate logistic regression models assessed the risk of PD for each urate range. Linear and quadratic terms were tested when modeling the association between urate and the risk of PD. Results: Women had significantly lower urate concentrations than did men [316.8 $\mu \mathrm{mol} / \mathrm{l}$ (SD 88.0) vs. $367.4 \mu \mathrm{mol} / \mathrm{l}$ (SD 87.7), $\mathrm{p}<0.0001$ ] and in women no associations between urate and PD risk were observed. In men, LOESS curves suggested a U-shaped or threshold effect between urate and PD risk. With the middle range as reference, the risk of developing PD was significantly increased for urate $<300 \mu \mathrm{mol} / \mathrm{I}$ (OR $1.69,95 \% \mathrm{Cl} 1.03-2.78)$ but not for urate $>500 \mu \mathrm{mol} / \mathrm{l}(\mathrm{OR}$
\end{abstract}

$1.55,95 \% \mathrm{Cl} 0.72-3.32)$ in men. A negative linear term was significant for urate $<500 \mu \mathrm{mol} / \mathrm{l}$, and across the entire range a convex quadratic term was significant. Conclusions: Results suggest a more complex relationship than previously reported between urate levels and the risk of PD in men. Low urate concentrations were associated with a higher PD risk and high urate concentrations were not associated with a further decrease in PD risk.

Copyright $\odot 2011$ S. Karger AG, Basel

\section{Introduction}

Urate is a natural antioxidant that has been found to prevent dopaminergic cell death in animal models of Parkinson disease (PD) [1]. Recent reports suggest that high urate concentrations in blood decrease the risk of $\mathrm{PD}$ and low urate concentrations may identify patients at increased risk for PD [2-6]. Evidence also suggests that urate can be a pro-oxidant through its direct toxic effects [7] or it can be a marker of a pro-oxidant state when its antioxidant effects are overwhelmed [8]. Given these conflicting possibilities, we approached the issue with a datadriven model using locally weighted scatterplot smoothing (LOESS) regression. Our objective was to quantify the association between urate concentration and incident PD

\section{KARGER}

두 2011 S. Karger AG, Basel

Fax +41613061234 E-Mail karger@karger.ch www.karger.com
Accessible online at: www.karger.com/ned
Samay Jain, MD, MS

Department of Neurology, University of Pittsburgh Medical Center

3471 Fifth Ave., Suite 811

Pittsburgh, PA 15213-3232 (USA)

Tel. +1 412692 4916, E-Mail jains@upmc.edu 
in an elderly community-based cohort of adults. Consistent with other epidemiological studies, we expected to find an inverse linear relationship between the baseline urate concentration and the risk of PD.

\section{Methods}

\section{Study Design and Population}

The Cardiovascular Health Study (CHS) is a communitybased cohort study of cardiovascular disease among 5,888 adults aged 65 years and older in whom data was prospectively collected for 14 years (1989-1993). Details of the study were previously published [9, 10]. Briefly, from 1989 to 1990, participants $(\mathrm{n}=5,201)$ were recruited from a random sample of Medicare-eligible persons in 4 US communities: Forsyth County, N.C.; Sacramento County, Calif.; Washington County, Md., and Pittsburgh, Pa. An additional cohort of 687 African-American men and women was recruited from 1992 to 1993. Participants were excluded if they were institutionalized, had cancer or other life threatening diseases, were planning to move out of the area within 3 years, or required a proxy to give consent. Participants were examined yearly, alternating with telephone interviews every 6 months from 1989 through 1999 for new diagnoses, hospitalizations, and medical procedures. After 1999, study visits ceased and data collection from telephone interviews and hospitalizations continued. Health Care Finance Administration records were also used to help enhance the surveillance of events and deaths. The institutional review board at each site approved the study methods, and all participants gave written informed consent.

\section{Identification of Incident PD Cases}

Details of PD case identification with the CHS were previously published [11]. Briefly, the following data sources were used to screen for PD cases:

(1) Self-report: The original cohort was asked if they had a physician's diagnosis of PD in the first year of follow-up and year 11. The African-American cohort was asked to report a physician's diagnosis of PD at baseline and year 11 .

(2) Medication inventory: At baseline and annual visits, participants were asked to report on and bring all vials for medications taken within 14 days of the visit. All medications were visually inspected, and their names, classes, doses, and frequencies were recorded. A movement disorders specialist (S.J.) reviewed antiparkinsonian medications to screen for potential PD. These medications included ethopropazine HCL (Parsidol ${ }^{\circledR}$ ), levodopa-containing compounds (Sinemet ${ }^{\circledR}$, Sinemet CR/ER ${ }^{\circledR}$, Larodopa ${ }^{\circledR}$, Dopar $^{\circledR}$, and Stalevo ${ }^{\circledR}$ ), pergolide (Per$\max ^{\circledR}$ ), pramipexole (Mirapex), ropinirole (Requip), bromocriptine $\left(\right.$ Parlodel $\left.^{\circledR}\right)$, selegiline $\left(\right.$ Eldepryl $^{\circledR}$, deprenyl ${ }^{\circledR}$, emsam $^{\circledR}$, and zelapar), rasagiline $\left(\right.$ Azilect $\left.{ }^{\circledR}\right)$, entacapone $\left(\right.$ Comtan $\left.{ }^{\circledR}\right)$, tolcapone $\left(\right.$ Tasmar $\left.^{\circledR}\right)$, ethopropazine $\left(\right.$ Parsdiol $\left.^{\circledR}\right)$, trihexyphenidyl HCL (Artane and Tremin), procyclidine (Kemadrin ${ }^{\circledR}$ ), biperiden $\left(\right.$ Akineton $\left.{ }^{\circledR}\right)$, benztropine $\left(\right.$ Cogentin $\left.{ }^{\circledR}\right)$, and amantadine (Symmetrel ${ }^{\circledR}$ ). Participants' response to these medications is not known. This data set preceded the time during which dopamine agonists (ropinirole and pramipexole) were widely used for restless legs syndrome (the earliest FDA approval for this condition was in 2005).
(3) Hospitalization records: Hospitalization discharge records included information on admission date, discharge date, vital status, and ICD-9 discharge codes for all hospitalizations of CHS subjects. We used ICD-9 code 332.0 to identify PD patients. Through June 2006, subjects [5,326 of 5,888 (90\%)] in the CHS were hospitalized.

A participant was identified as PD if at least 1 of the above sources supporting PD was present. Each participant with PD was assigned a date of first evidence corresponding to the earliest evidence of PD from any of the above mentioned data sources. If this date was during the period of baseline through the first year of follow-up, the participant was defined as having prevalent PD. Those with a date of first evidence during subsequent follow-up were considered to have incident PD. Medications were screened for agents that could potentially induce parkinsonism. If the first evidence of such drugs occurred at the same time or before the date of the first evidence of PD, these PD were reclassified as nonPD.

\section{Measurement of Serum Urate and Covariates}

Serum urate concentrations $(\mu \mathrm{mol} / \mathrm{l})$ were measured at baseline after an 8-hour fast. Detailed methods for blood drawing, quality assurance, and assay performance were published previously [12]. Serum chemistry tests, including creatinine, were preformed using a Kodak Ektachem 700 Analyzer (Eastman Kodak, Rochester, N.Y., USA), a calorimetric method. The coefficient of variation for urate was $1.2 \%$ [13]. Serum creatinine was calibrated indirectly to the Cleveland Clinic 'standard' assay used in the development of the Modification of Diet in Renal Disease Study glomerular filtration rate prediction equation [14].

Information on covariates, including basic demographics (i.e. age, sex, and race), smoking status, and consumption of caffeine (for the 1989-1990 cohort only) and alcohol, was obtained at baseline interviews. Participants were current smokers if they reported smoking within the past 30 days or said they currently smoked. Former and never smokers were classified on the basis of self-reported smoking status and reported no cigarette smoking in the past 30 days. Body mass index was computed as weight $(\mathrm{kg}) \mathrm{di}-$ vided by height $(\mathrm{m})$ squared. Other covariates used for analyses included hypertension, diabetes, EKG abnormalities, and uricosurics. Hypertension was defined as systolic blood pressure $\geq 140$ $\mathrm{mm} \mathrm{Hg}$ or diastolic blood pressure $\geq 90 \mathrm{~mm} \mathrm{Hg}$, or self-reported diagnosis of high blood pressure and use of antihypertensive medications. Diabetes was defined as the use of insulin or oral hypoglycemic agents or a fasting glucose level $\geq 126 \mathrm{mg} / \mathrm{dl}$. EKG abnormalities were based on Minnesota codes as detailed previously [15].

\section{Data Analysis}

Participants who did not have their baseline uric acid measured were excluded ( $\mathrm{n}=139 ; 2.4 \%$ ) leaving 5,749 for analysis. Because we observed a sex difference in urate concentrations we conducted analyses for men and women separately. As discussed above, urate has been reported as both a pro-oxidant and an antioxidant and thus could potentially either increase or decrease the risk of PD. For that reason, we chose not to predict the association between baseline urate concentrations and the risk of PD a priori. Rather, the initial analyses involved data-driven LOESS smoothed curves plotted with the baseline serum urate concentration against the probability of incident PD, from which 3 cat- 
Fig. 1. LOESS plots. Based on the LOESS curve for men, we categorized urate as $<300 \mu \mathrm{mol} / \mathrm{l}$ (low), 300-500 $\mu \mathrm{mol} / \mathrm{l}$ (middle), and $>500 \mu \mathrm{mol} / \mathrm{l}$ (high), as shown by the vertical lines.

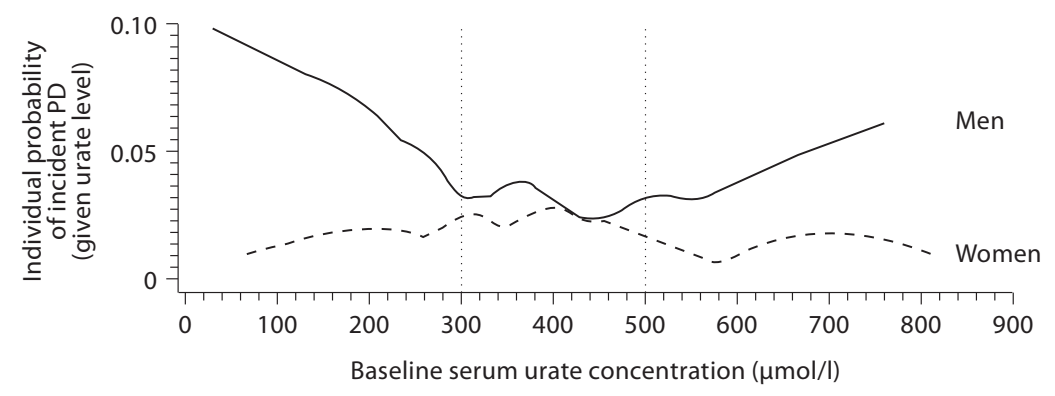

years of follow-up, 60 of which were prevalent cases observed at baseline and were excluded from the analyses. The remaining 154 were considered incident PD cases [74 were identified by self-report, 71 by medications, 96 by hospitalization records (ICD-9), 63 by more than 1 data source, and 24 by all 3 data sources]. The study cohort was $84.2 \%$ Caucasian with an average age of 72.8 (SD 5.6) and a mean follow-up of 10.37 (SD 3.81) years. Women had significantly lower urate concentrations than did men [316.8 $\mu \mathrm{mol} / \mathrm{l}$ (SD 88.0) vs. $367.4 \mu \mathrm{mol} / \mathrm{l}$ (SD 87.7), $\mathrm{p}<$ $0.0001]$. In men, LOESS plots of an individual's baseline urate concentration against their probability of incident PD cases suggested a U-shaped relationship with 3 distinct regions: a negative slope for urate $<300 \mu \mathrm{mol} / \mathrm{l}$, followed by a slope oscillating between positive and negative values for urate $300-500 \mu \mathrm{mol} / \mathrm{l}$, and then a positive slope for urate $>500 \mu \mathrm{mol} / \mathrm{l}$ (fig. 1). This pattern was not seen in women. Using low-, middle-, and high-urate groups, low urate concentrations were associated with a higher prevalence of diabetes in men and a lower prevalence of diabetes and a high body mass index in women. In both sexes, urate was positively associated with the presence of hypertension and EKG abnormalities (table 1).

\section{Association between Uric Acid and Incident PD}

Among men, compared to the group with mid-range urate concentrations $(300-500 \mu \mathrm{mol} / \mathrm{l})$, the low-urate group was associated with a significantly elevated risk of $\mathrm{PD}$ in age- and smoking-adjusted models (OR 1.69, 95\% CI 1.03-2.78, $\mathrm{p}=0.04$ ), but the higher PD risk for the high urate group was not significant (OR 1.55, 95\% CI $0.72-$ $3.32, \mathrm{p}=0.26$ ). Among women, none of the differences in the risk of PD among the 3 urate groups was significant. Results from the fully adjusted models were similar to those in the age- and smoking-adjusted models (table 2). The fully adjusted model showed a trend for significance 
Table 1. Population characteristics

\begin{tabular}{|c|c|c|c|c|c|c|}
\hline \multirow[t]{2}{*}{ Baseline urate range $(\mu \mathrm{mol} / \mathrm{l})$} & \multicolumn{3}{|l|}{ Men $(n=2,434)$} & \multicolumn{3}{|c|}{ Women $(n=3,315)$} \\
\hline & $\begin{array}{l}\text { low }(<300) \\
\mathrm{N}_{\text {total }}=492 \\
\mathrm{~N}_{\mathrm{PD}}=24\end{array}$ & $\begin{array}{l}\text { middle }(300-500) \\
\mathrm{N}_{\text {total }}=1,763 \\
\mathrm{~N}_{\mathrm{PD}}=52\end{array}$ & $\begin{array}{l}\text { high }(>500) \\
\mathrm{N}_{\text {total }}=179 \\
\mathrm{~N}_{\mathrm{PD}}=8\end{array}$ & $\begin{array}{l}\text { low }(<300) \\
\mathrm{N}_{\text {total }}=1,542 \\
\mathrm{~N}_{\mathrm{PD}}=27\end{array}$ & $\begin{array}{l}\text { middle }(300-500) \\
\mathrm{N}_{\text {total }}=1,661 \\
\mathrm{~N}_{\mathrm{PD}}=41\end{array}$ & $\begin{array}{l}\text { high }(>500) \\
\mathrm{N}_{\text {total }}=112 \\
\mathrm{~N}_{\mathrm{PD}}=2\end{array}$ \\
\hline Participants, n (\%) & $492(20.2)$ & $1,763(72.4)$ & $179(7.4)$ & $1,542(46.5)$ & $1,661(50.1)$ & $112(3.4)$ \\
\hline Mean urate $(\mathrm{SD})$ & $259.1(36.9)^{\mathrm{a}, \mathrm{b}}$ & $382.7(52.4)$ & $558.9(54.9)^{\mathrm{a}}$ & $244.9(40.1)^{\mathrm{a}, \mathrm{b}}$ & $367.5(50.8)$ & $554.8(52.1)^{\mathrm{a}}$ \\
\hline Range & $29.7-297.4$ & $303.4-499.6$ & $505.6-761.3$ & $71.4-297.4$ & $303.4-499.6$ & $505.6-814.9$ \\
\hline Mean baseline age, years (SD) & $73.3(5.5)$ & $73.2(5.8)$ & $73.4(5.0)$ & $72.3(5.3)$ & $72.6(5.5)$ & $73.5(6.9)$ \\
\hline \multicolumn{7}{|l|}{ Race, $\mathrm{n}(\%)$} \\
\hline Caucasian & $426(86.6)^{b}$ & $1,518(86.1)$ & $144(80.4)^{\mathrm{a}}$ & $1,326(86.0)^{\mathrm{a}, \mathrm{b}}$ & $1,342(80.8)$ & $83(74.1)$ \\
\hline African-American & $64(13.0)$ & $234(13.3)$ & $32(17.9)$ & $207(13.4)^{\mathrm{a}, \mathrm{b}}$ & $307(18.5)$ & $29(25.9)$ \\
\hline Other & $2(0.4)$ & $11(0.6)$ & $3(1.7)$ & $9(0.6)$ & $12(0.7)$ & $0(0.0)$ \\
\hline \multicolumn{7}{|l|}{ Smoking, n (\%) } \\
\hline Never & $158(32.2)$ & $567(32.2)$ & $52(29.1)$ & $889(57.7)$ & $934(56.3)$ & $58(51.8)$ \\
\hline Former & $263(53.6)$ & $1,015(57.6)$ & $110(61.5)$ & $454(29.5)$ & $518(31.2)$ & $40(35.7)$ \\
\hline Current & $70(14.3)^{\mathrm{a}}$ & $179(10.2)$ & $17(9.5)$ & $197(12.8)$ & $208(12.5)$ & $14(12.5)$ \\
\hline Coffee drinking ${ }^{\mathrm{c}}, \mathrm{n}(\%)$ & $279(63.1)^{\mathrm{a}}$ & $1,109(69.5)$ & $108(70.1)$ & $849(61.1)$ & $890(61.8)$ & $46(52.3)$ \\
\hline Body mass index & $25.3(3.8)$ & $26.7(3.7)$ & $27.3(4.0)$ & $25.2(4.6)^{\mathrm{a}, \mathrm{b}}$ & $28.2(5.3)^{\mathrm{c}}$ & $30.1(6.4)^{\mathrm{a}}$ \\
\hline \multicolumn{7}{|l|}{ Alcohol consumption } \\
\hline drinks/week & $3.1(7.1)$ & $3.8(7.6)$ & $3.7(7.2)$ & $1.5(4.3)$ & $1.5(4.4)$ & $2.2(6.8)$ \\
\hline Baseline creatinine, mg/dl & $1.1(0.4)^{\mathrm{a}, \mathrm{b}}$ & $1.2(0.4)$ & $1.6(0.6)^{\mathrm{a}}$ & $0.9(0.3)^{\mathrm{a}, \mathrm{b}}$ & $1.0(0.3)^{\mathrm{c}}$ & $1.3(0.6)^{\mathrm{a}}$ \\
\hline \multicolumn{7}{|l|}{ Other medical conditions, $\mathrm{n}(\%)$} \\
\hline Diabetes & $127(25.8)^{\mathrm{a}, \mathrm{b}}$ & $303(17.2)$ & $30(16.8)$ & $169(11.0)^{\mathrm{a}, \mathrm{b}}$ & $265(16.0)^{\mathrm{c}}$ & $32(28.6)^{\mathrm{a}}$ \\
\hline Hypertension & $151(30.7)^{\mathrm{a}, \mathrm{b}}$ & $727(41.3)$ & $116(64.8)^{\mathrm{a}}$ & $558(36.2)^{\mathrm{a}, \mathrm{b}}$ & $891(53.7)^{\mathrm{c}}$ & $92(82.1)^{\mathrm{a}}$ \\
\hline EKG abnormality & $159(33.1)^{\mathrm{b}}$ & $621(36.4)$ & $26(49.7)^{\mathrm{a}}$ & $327(21.9)^{\mathrm{a}, \mathrm{b}}$ & $435(27.3)^{\mathrm{c}}$ & $52(48.6)^{\mathrm{a}}$ \\
\hline $\begin{array}{l}\mathrm{N}_{\text {total }}=\text { Total number of par } \\
{ }^{\mathrm{a}} \mathrm{p}<0.05 \text { versus the middle } \\
{ }^{\mathrm{b}} \mathrm{p}<0.05 \text { versus the high ur } \\
{ }^{\mathrm{c}} \text { Baseline data and percenta }\end{array}$ & $\begin{array}{l}\text { ints; } \mathrm{N}_{\mathrm{PD}}=\mathrm{nl} \\
\text { range. } \\
\text { nge. All tests }\end{array}$ & $\begin{array}{l}\text { er of } \mathrm{PD} \text { cases; } \\
2 \text { sided, } \mathrm{p}<0.0\end{array}$ & Selont & & & \\
\hline
\end{tabular}

Table 2. Associations between the baseline urate concentration and incident PD

\begin{tabular}{|c|c|c|c|c|c|}
\hline \multirow[t]{2}{*}{ Baseline urate $(\mu \mathrm{mol} / \mathrm{l})$} & \multirow[t]{2}{*}{ Model } & \multicolumn{2}{|l|}{ Men } & \multicolumn{2}{|l|}{ Women } \\
\hline & & OR & $95 \% \mathrm{CI}$ & OR & $95 \%$ CI \\
\hline Urate $<300 \mu \mathrm{mol} / \mathrm{l}$ & 1 & 1.69 & $1.03-2.78$ & 0.69 & $0.43-1.14$ \\
\hline $\mathrm{N}_{\mathrm{PD} \text { men }}=24, \mathrm{~N}_{\mathrm{PD} \text { women }}=27$ & 2 & 1.69 & $1.02-2.79$ & 0.71 & $0.43-1.17$ \\
\hline Urate $300-500 \mu \mathrm{mol} / \mathrm{l}$ & 1 & 1.0 (ref.) & - & 1.0 (ref.) & - \\
\hline $\mathrm{N}_{\mathrm{PD} \text { men }}=52, \mathrm{~N}_{\mathrm{PD} \text { women }}=41$ & 2 & 1.0 (ref.) & - & 1.0 (ref.) & - \\
\hline Urate $>500 \mu \mathrm{mol} / \mathrm{l}$ & 1 & 1.55 & $0.72-3.32$ & 0.75 & $0.18-3.16$ \\
\hline $\mathrm{N}_{\mathrm{PD} \text { men }}=8, \mathrm{~N}_{\mathrm{PD} \text { women }}=2$ & 2 & 1.31 & $0.58-2.94$ & 0.82 & $0.20-3.50$ \\
\hline
\end{tabular}

$\mathrm{N}_{\mathrm{PD}}=$ Number of incident PD cases; model 1 = adjusted for age and smoking; model 2 = additionally adjusted for race, body mass index, alcohol consumption, creatinine, diabetes, hypertension, uricosurics, and EKG abnormalities. 
in a lower risk of PD for the ever smokers covariate in women (OR 0.61, 95\% CI 0.36-1.03, p = 0.06). In men, only diabetes was a significant covariate for a higher PD risk (OR 1.67, 95\% CI 1.02-2.75, p = 0.04) and a trend was seen with EKG abnormalities (OR 1.51, 95\% CI 0.96-2.38, $\mathrm{p}=0.06$ ). The model was repeated evaluating uric acid as a continuous variable in men. For urate $<500 \mu \mathrm{mol} / \mathrm{l}$, a negative linear term was significant $(\mathrm{p}=0.03)$ for the ageand smoking-adjusted model, but it was not significant for the entire urate range $(\mathrm{p}=0.12)$. A convex quadratic term centered at $500 \mu \mathrm{mol} / \mathrm{l}$ was significant for the entire range $(p=0.04)$. Neither linear nor quadratic terms were significant in models restricted to women. In the sensitivity analysis excluding PD cases through the first 5 years of follow-up, the results remained significant and consistent with the primary analyses (data not shown). Results of the analysis of PD cases identified by more than 1 data source were not significant; this is likely due to small sample sizes as $41 \%(63 / 154 ; 40$ men) of the incident PD cases were included with the low and high urate groups containing 6 and 3 men with incident PD, respectively.

\section{Discussion}

Our primary analyses with LOESS regression suggested 3 distinct ranges of urate as they relate to PD risk in men. An inverse relationship was seen between PD risk and urate for the low range of urate $(<300 \mu \mathrm{mol} / \mathrm{l})$, followed by the middle range with no clear association for urate $(300-500 \mu \mathrm{mol} / \mathrm{l})$ and then a positive association between PD risk and urate in the high range $(>500$ $\mu \mathrm{mol} / \mathrm{l}$ ) (fig. 1). The low-urate group was at a higher risk for PD compared to the middle-urate group. In men, we found an inverse linear relationship between the baseline urate concentration and the risk of PD for urate $<500$ $\mu \mathrm{mol} / \mathrm{l}$, and a convex quadratic relationship was found across the entire urate range.

Lower urate concentrations associated with a higher risk of $\mathrm{PD}$ have been reported in other prospective studies including: the Atherosclerosis Risk in Communities (ARIC) cohort [6], the Honolulu Heart Program [3], the Health Professionals Follow Up study [4], and the Rotterdam study [2]. The ARIC and Rotterdam cohorts included women, and while the Rotterdam study only reported an association between higher urate and a lower risk of $\mathrm{PD}$ in analyses which combined both sexes, this association was only seen in men in the ARIC study and it was not seen in women in the Nurses Health Study [16]. To date, the data are very limited in women and clearer in men. One could speculate that the stronger association in men compared to women could be due to a biological effect of sex on urate mechanisms in PD, as estrogen increases mitochondrial respiration efficiency, resulting in a lower oxidative load [17]. The difference may also reflect lower urate concentrations or a lower incidence of PD in women compared to men. This highlights the need for further study, particularly in women.

Unlike other studies, we found that the inverse relationship between urate and the risk of PD in the low-tomid urate range did not persist at higher urate concentrations. Although a convex quadratic term was significant for the entire range, the data does not convincingly support high urate being a risk factor for PD. The lack of significance for a higher risk of PD in the high-urate category could be because of the small number of participants in the high range, the possibility of some misclassification of PD cases, or the age at which urate was measured (the CHS cohort is older and the plasma urate concentration increases with age). It is also possible that there really is no association of higher urate concentrations with PD, which would contradict other studies discussed above that report a lower risk of PD with higher urate concentrations. An alternative explanation for the Ushaped relationship is a threshold effect, with low urate $(<300 \mu \mathrm{mol} / \mathrm{l})$ being associated with a higher PD risk while at higher concentrations no further effect is seen. Either a U-shaped effect or a threshold effect is plausible given that while urate is an antioxidant it may also indicate a pro-oxidative state under certain circumstances [7]. In conditions of oxidative stress an increased production of urate occurs in parallel with the increase in reactive oxygen species. This leads to supernormal levels of urate. In situations with particularly high oxidative stress, the anti-oxidant effort of urate is overcome by the prooxidant or proinflammatory effects of reactive oxygen species accumulation [8]. In the CHS, urate has been positively associated with the preexistence and progression of chronic kidney disease [13] and negatively associated with systolic blood pressure [18]. Urate has also been positively associated with incident heart failure only when it is a marker of increased xanthine oxidase activity (an enzyme that generates urate as a byproduct of its metabolic function). Urate is not associated with incident heart failure when it reflects reduced kidney function [19].

A more complex relationship than previously reported was seen between urate and PD risk, possibly due to methodology and study population characteristics. Prior studies have either analyzed urate as a continuous variable or categorized it into quartiles or quintiles. We used 
LOESS to develop a data-driven categorization of urate as it relates to PD. Our cohort is older than the others that have been reported and the cutoff for the highest urate category in this study is $>500 \mu \mathrm{mol} / \mathrm{l}$, which is higher than the cutoff for the highest category in other studies (e.g. $>374 \mu \mathrm{mol} / \mathrm{l}$ in the Rotterdam study [2] and $>404$ $\mu \mathrm{mol} / \mathrm{l}$ in the Honolulu Heart Study [3]).

A limitation is that there was no systematic neurological examination of all CHS participants to validate a PD diagnosis. Moreover, there was no exact date of PD diagnosis available. Unfortunately, most of the CHS cohort is now deceased, so clinical validation of PD cases is not possible. It is likely that some misclassification of PD cases occurred which attenuated our results. However, we have indirectly validated our PD classification by finding the expected inverse association with smoking [11] using the same types of data sources to identify PD as published in other cohorts [6]. A particular concern in the CHS may be that vascular parkinsonism cases were misclassified as PD. However if this occurred one would not expect the negative association between PD cases and smoking given the opposite (positive) association between smoking and cerebrovascular disease. A sensitivity analysis with more restrictive criteria for PD (at least 2 supporting data sources) did not remain significant, likely due to the small number of remaining incident PD cases though the possibility of misclassification cannot be excluded. We used a consistent definition of 'date of earliest evidence' as a surrogate to the date of PD diagnosis and excluded all prevalent cases including those within the first year of follow-up. Nonetheless, we were unable to definitively differentiate incident cases from prevalent cases. Because of uncertainty regarding diagnosis dates we used logistic regression and not proportional hazards modeling. A sensitivity analysis with more restrictive criteria for incident PD cases (only cases of PD with a date of earliest evidence more that 5 years after baseline) yielded results which remained significant and consistent with the primary analyses.

A strength of the CHS is that it was done in an elderly, racially diverse, community-based population from 5 different locations with 14 years of follow-up in which $>97 \%$ had baseline serum urate levels. In our analyses both diabetes and EKG abnormalities were associated with an elevated risk of PD; therefore, we considered them as potential confounders as associations between hyperuricemia and both coronary disease and insulin resistance are well established [20]. Although this raises the possibility that some cases classified as PD were in fact cases of vascular parkinsonism, neuropathological stud- ies demonstrate degenerative changes in both cardiac sympathetic nerves and the pancreas in PD autopsies [21, 22 ] and 1 case-control study found diabetes to be associated with a decreased risk of PD [23].

\section{Conclusions}

In men, low urate concentrations were associated with a higher PD risk and high urate concentrations were not associated with a further decrease in PD risk. If higher urate concentrations do not confer a further lowering of the risk of $\mathrm{PD}$, this would be relevant to ongoing interventional studies of the effects of urate supplementation on the progression of PD as high urate concentrations may increase the risk of gout, cardiovascular disease, or kidney disease $[13,24]$. More research is needed to confirm our preliminary findings and fully understand urate's physiological effects.

\section{Acknowledgements}

This study was funded by the University of Pittsburgh Claude D. Pepper Older Americans Independence Center (P30 AG024827), the NHLBI (N01 HC-35129, N01 HC-45133, N01 HC75150, N01 HC-85079 through N01 HC-85086, N01 HC-15103, N01 HC-55222, U01 HL-080295, and R01 HL-075366), the NINDS, the NIA (R01 AG-023629, R01 AG-15928, R01 AG-20098, and R01 AG-027058), NHLBI T32 training grant HL007902, and the University of Pittsburgh Clinical Research Scholars Program (1 KL2 RR024154-01).

\section{Disclosure Statement}

The authors have nothing to disclose.

References Parkinson's disease. Mov Disord 2008;23: 1653-1657.

-2 de Lau LM, Koudstaal PJ, Hofman A, Breteler MM: Serum uric acid levels and the risk of Parkinson disease. Annals Neurol 2005; 58:797-800.

- 3 Davis JW, Grandinetti A, Waslien CI, Ross GW, White LR, Morens DM: Observations on serum uric acid levels and the risk of idiopathic Parkinson's disease. Am J Epidemiol 1996;144:480-484

-4 Weisskopf MG, O’Reilly E, Chen H, Schwarzschild MA, Ascherio A: Plasma urate and risk of Parkinson's disease. Am J Epidemiol 2007; 166:561-567. 
5 Annanmaki T, Muuronen A, Murros K: Low plasma uric acid level in Parkinson's disease. Mov Disord 2007;22:1133-1137.

6 Chen HM, Mosley TH, Alonso A, Huang X: Plasma urate and Parkinson's disease in the Atherosclerosis Risk in Communities (ARIC) Study. American J Epidemiol 2009; 169:1064-1069.

7 Lippi G, Montagnana M, Franchini M, Favaloro EJ, Targher G: The paradoxical relationship between serum uric acid and cardiovascular disease. Clin Chim Acta 2008; 392:1-7.

8 Strazzullo P, Puig JG: Uric acid and oxidative stress: relative impact on cardiovascular risk? Nutr Metab Cardiovasc Dis 2007;17: 409-414.

$\checkmark 9$ Fried LP, Borhani NO, Enright P, et al: The Cardiovascular Health Study: design and rationale. Ann Epidemiol 1991;1:263-276.

-10 Tell GS, Fried LP, Hermanson B, Manolio TA, Newman AB, Borhani NO: Recruitment of adults 65 years and older as participants in the Cardiovascular Health Study. Ann Epidemiol 1993;3:358-366.

- 11 Ton TG, Jain S, Boudreau B, Thacker EL, Strotmeyer ES, Newman AB, Longstreth WT, Checkoway H: Post hoc Parkinson's: Identifying an uncommon disease in the Cardiovascular Health Study. Neuroepidemiology 2010;35:241-249.
12 Cushman M, Cornell ES, Howard PR, Bovill EG, Tracy RP: Laboratory methods and quality assurance in the Cardiovascular Health Study. Clin Chem 1995;41:264-270.

13 Chonchol M, Shlipak MG, Katz R, et al: Relationship of uric acid with progression of kidney disease. Am J Kidney Dis 2007;50: 239-247.

14 Shlipak MG, Fried LF, Cushman M, et al: Cardiovascular mortality risk in chronic kidney disease: comparison of traditional and novel risk factors. JAMA 2005;293:17371745.

15 Kumar A, Prineas RJ, Arnold AM, et al: Prevalence, prognosis, and implications of isolated minor nonspecific ST-segment and T-wave abnormalities in older adults: Cardiovascular Health Study. Circulation 2008; 118:2790-2796.

16 O'Reilly EJ, Gao X, Weisskopf MG, et al: Plasma urate and Parkinson's disease in women. Am J Epidemiol 2010;172:666-670.

17 Nilsen J, Brinton RD: Mitochondria as therapeutic targets of estrogen action in the central nervous system. Curr Drug Targets CNS Neurol Disord 2004;3:297-313.
18 Tell GS, Rutan GH, Kronmal RA, et al: Correlates of blood pressure in communitydwelling older adults: the Cardiovascular Health Study. Cardiovascular Health Study (CHS) Collaborative Research Group. Hypertension 1994;23:59-67.

19 Ekundayo OJ, Dell'Italia LJ, Sanders PW, et al: Association between hyperuricemia and incident heart failure among older adults: a propensity-matched study. Int J Cardiol 2010;142:279-287.

20 Edwards NL: The role of hyperuricemia in vascular disorders. Curr Opin Rheumatol 2009;21:132-137.

21 Beach TG, Adler CH, Sue LI, et al: Multi-organ distribution of phosphorylated alphasynuclein histopathology in subjects with Lewy body disorders. Acta Neuropathol 2010;119:689-702.

22 Orimo S, Uchihara T, Nakamura A, et al: Axonal alpha-synuclein aggregates herald centripetal degeneration of cardiac sympathetic nerve in Parkinson's disease. Brain 2008;131: 642-650.

-23 Miyake Y, Tanaka K, Fukushima W, et al: Case-control study of risk of Parkinson's disease in relation to hypertension, hypercholesterolemia, and diabetes in Japan. J Neurol Sci 2010;293:82-86.

24 Shah A, Keenan RT: Gout, hyperuricemia, and the risk of cardiovascular disease: cause and effect? Curr Rheumatol Rep 2010;12: 118-124. 